\title{
Infrasound array criteria for automatic detection and front velocity estimation of snow avalanches: towards a real-time early-warning system
}

\author{
E. Marchetti ${ }^{1}$, M. Ripepe ${ }^{1}$, G. Ulivieri ${ }^{2}$, and A. Kogelnig ${ }^{3}$ \\ ${ }^{1}$ Depart. of Earth Sciences, University of Firenze, via G. La Pira 4, 50121, Firenze, Italy \\ ${ }^{2}$ Item s.r.l., via B. Gozzoli 32, 50124, Firenze, Italy \\ ${ }^{3}$ Wyssen Avalanche Control AG, Feld 1, 3713 Reichenbach, Switzerland
}

Correspondence to: E. Marchetti (emanuele.marchetti@unifi.it)

Received: 11 March 2015 - Published in Nat. Hazards Earth Syst. Sci. Discuss.: 17 April 2015

Revised: 5 November 2015 - Accepted: 13 November 2015 - Published: 30 November 2015

\begin{abstract}
Avalanche risk management is strongly related to the ability to identify and timely report the occurrence of snow avalanches. Infrasound has been applied to avalanche research and monitoring for the last 20 years but it never turned into an operational tool to identify clear signals related to avalanches. We present here a method based on the analysis of infrasound signals recorded by a small aperture array in Ischgl (Austria), which provides a significant improvement to overcome this limit. The method is based on array-derived wave parameters, such as back azimuth and apparent velocity. The method defines threshold criteria for automatic avalanche identification by considering avalanches as a moving source of infrasound. We validate the efficiency of the automatic infrasound detection with continuous observations with Doppler radar and we show how the velocity of a snow avalanche in any given path around the array can be efficiently derived. Our results indicate that a proper infrasound array analysis allows a robust, real-time, remote detection of snow avalanches that is able to provide the number and the time of occurrence of snow avalanches occurring all around the array, which represent key information for a proper validation of avalanche forecast models and risk management in a given area.
\end{abstract}

\section{Introduction}

Operational avalanche forecast is based on the combination of observations and models of the snowpack and weather, which are validated by on-site observation of avalanche occurrence (McClung and Schaerer, 2006). Natural avalanche activity is a clear sign of instability and is thus often considered as the best warning for further events. However, avalanche activity estimated by visual observations is limited by bad weather and is impossible at night. This usually prevents us from knowing the exact time of the occurrence of the event, thus resulting in a poor correlation with forecast models and a poor estimate of the danger (Schweizer et al., 2003). For this reason, the precise timing of avalanche activity available also at night or during periods of poor visibility and in remote areas would significantly improve operational avalanche forecasting.

Videogrammetry (e.g., Vallet et al., 2004) and radars (e.g., Rammer et al., 2007; Vriend et al., 2013) are among the most common geophysical methods to detect snow avalanches. They measure directly the physical characteristics of an avalanche front but are limited to single paths analysis. Radar measurements of snow avalanches are considered extremely reliable, being able to measure directly the front velocity of the flow in different range gates and providing an estimate of the avalanche size and the precise time of occurrence of an event. Doppler radars are commonly used to notify avalanche occurrence in real time and are used both for risk management and operational avalanche forecasting (Kogelnig et al., 2012). This technique is, however, limited to one 
single avalanche path, thus resulting in quite high operational costs.

Infrasound (e.g., Bedard, 1989) and seismic observations (e.g., Schaerer and Salway, 1980) measure the energy radiated by the avalanche, respectively, in the atmosphere and in the ground, and are able to detect snow avalanches over large areas and moving along multiple paths. These different monitoring techniques have been used both during temporary experiments and operationally for real-time nowcasting.

Seismic measurements are widely used both for monitoring and research on snow avalanches in many countries worldwide (e.g., Schaerer and Salway, 1980; Kishimura and Izumi, 1997; Leprette et al., 1998, Surinach et al., 2000; van Herwijnen and Schweizer, 2011). Seismic observations provide time of occurrence of snow avalanches regardless of the visibility conditions. Seismic measurements have also been used extensively to investigate avalanche dynamics and characteristics by using multiple sensors along a single avalanche path (e.g., Sabot et al., 1998; Vilajosana et al., 2007). More recently, seismic arrays have been shown to allow location of snow avalanches and evaluation of avalanche front speed also at distances of $\sim 3 \mathrm{~km}$ (Lacroix et al., 2012).

The use of infrasound for avalanche monitoring has been increasing rapidly in the last decades, with significant improvements also on avalanche dynamics research (Bedard, 1989; Chritin et al., 1996; Adam et al., 1998; Comey and Mendenhall, 2004; Scott et al., 2007; Ulivieri et al., 2011; Kogelnig et al., 2011; Havens et al., 2014; Thüring et al., 2015). After the initial works with single infrasound sensors (e.g., Bedard, 1989), the use of infrasound arrays has improved significantly the signal-to-noise ratio (e.g., Scott et al. 2007; Ulivieri et al., 2011; Havens et al., 2014), thus resulting in a larger efficiency of infrasound in detecting snow avalanches even at larger (few km) distances. Array processing techniques showed that back azimuth and apparent velocity of infrasound generated by snow avalanches nicely trace the downhill moving front at a source-to-receiver distance of $2 \mathrm{~km}$ (Ulivieri et al., 2011) and can be used to evaluate avalanche front velocity (Havens et al., 2014). Recently, a network of three infrasound arrays deployed in three different valleys in Valle d'Aosta, Italy, allowed Ulivieri et al., 2012) to detect and locate a size-3 avalanche at a sourceto-receiver distance of $\sim 20 \mathrm{~km}$.

The use of infrasound array as a monitoring tool for automatic identification of signals from snow avalanches is not fully addressed yet. Scott et al. (2007) showed how array analysis allows increasing the signal-to-noise ratio of infrasound radiated by snow avalanches to support automatic avalanche identification. Ulivieri et al. (2011) first compared results from array analysis of infrasound collected during the 2009-2010 winter season and avalanche activity in the area, while more recently Thüring et al. (2015) showed results of supervised machine learning analysis applied to infrasound data recorded during the 2011-2012 winter season in the eastern Swiss Alps. However, a systematic comparison of automatic avalanche identification with infrasound data and real avalanche activity is still missing. This is mainly because automatic identification of snow avalanches based on infrasonic waveform can be extremely ambiguous and still requires careful analysis. Snow avalanches are typically recorded as emergent, long-lasting (tens of seconds) infrasonic signals peaking typically at $1-5 \mathrm{~Hz}$ (Bedard, 1989; Kogelnig et al., 2011; Ulivieri et al., 2011), and a similar infrasonic waveform might result from a wide variety of natural (earthquakes, meteors, thunders) or anthropogenic (traffic, explosions) source processes.

In this work we present results on automatic avalanche identification and evaluation of the avalanche front velocity obtained with an infrasound array, which operated during the 2012-2013 winter season near Ischgl (Paznaun valley, Austria), monitoring events from the Grosstal avalanche channel where spontaneous and controlled events typically occur every year (Jöbstl et al., 2014). The Grosstal avalanche channel is monitored permanently with a pulsed Doppler radar (Kogelnig et al., 2012), and we use it here to evaluate results obtained with the infrasound array.

We first present a detailed analysis of an avalanche which occurred in the Grosstal channel on 23 December 2012 and use infrasound wave parameters (back azimuth and apparent velocity) derived from array analysis for this specific event to derive instantaneous front velocity and to fix thresholds to be used for automatic avalanche detection. We then perform analysis over the whole data set collected during the 20122013 winter season and show eventually how infrasound can be efficiently used as a real-time early-warning system over large areas.

\section{Radar and infrasound observations of the Grosstal avalanche}

The Grosstal avalanche channel, positioned on the northern flank of the Paznaun valley near the town of Ischgl (Austria), is typically characterized by the occurrence of several events/year (Jöbstl et al., 2014), with avalanches reaching the Silvretta road every 10 years (Fig. 1). The avalanche has a starting zone of $160000 \mathrm{~m}^{2}$ and a path length of $1800 \mathrm{~m}$ from the release area down ( $2250 \mathrm{~m}$ a.s.l.) to the bottom of the valley (1360 m a.s.1.).

Between December 2012 and May 2013 avalanche activity in the Paznaun valley was moderate and controlled avalanche release was performed regularly, both in the ski resort as well as along the road. The largest event during our observation period occurred in the morning of 23 December 2012, after an intense snowfall, with avalanche deposit almost reaching the Silvretta road (Fig. 1b). At the time of occurrence of the event it was snowing in the accumulation zone while it was raining at lower elevation. Therefore the event started as a dry avalanche and turned into a wet avalanche at lower elevation. In the following sections we present radar observations 


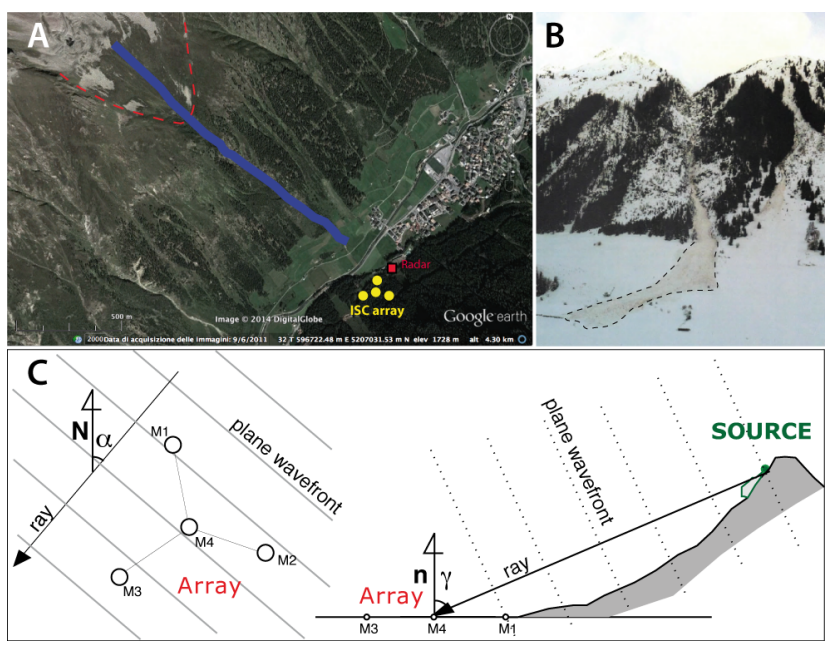

Figure 1. (a) Google Earth view of the Paznaun valley near Ischgl (Austria), showing the position of the Grosstal avalanche path (blue line) and starting area (dashed red line) and the position of the monitoring radar (red square) and the infrasound array (yellow circles) deployed during the 2012/2013 winter season. (a) Picture of the 23 December 2012 Grosstal avalanche taken in the morning $\sim 7-8 \mathrm{~h}$ after the event. (c) Sketch of infrasound array geometry and corresponding wave parameters: notation of back azimuth $(\alpha)$ and takeoff angle $(\gamma)$ is the same as in the text.

of the event and compare it with information derived from infrasound array analysis.

\subsection{The avalanche Doppler radar}

The Grosstal avalanche channel is permanently monitored with pulsed Doppler radar, which can reliably detect avalanche activity up to distances of $2.5 \mathrm{~km}$ and is able to measure velocity ranging between 0.3 and $80 \mathrm{~m} \mathrm{~s}^{-1}$ in nine different range gates (Kogelnig et al., 2012). In the specific case of the Grosstal avalanche, the radar is facing directly the avalanche path from a distance of $\sim 1800 \mathrm{~m}$ and it focuses on the starting zone and the upper track. The target area of the radar extends for about $\sim 1000 \mathrm{~m}$ of ground distance out of the whole $\sim 1900 \mathrm{~m}$ horizontal length of the avalanche path (between $\sim 250$ and $\sim 1200 \mathrm{~m}$ ground distance from the avalanche starting point) and covers an elevation difference of $\sim 600 \mathrm{~m}$, from 2100 to $1500 \mathrm{~m}$ a.s.l. (Fig. 2). Because of the morphology of the channel, the radar is not able to cover the entire avalanche path (Fig. 2a), and events outside the range gates are not detected (Kogelnig et al., 2012).

The velocity profile measured along the line of sight of the Doppler radar for the 23 December 2012 avalanche (Fig. 2c) is showing a continuous increase in velocity up to $15 \mathrm{~m} \mathrm{~s}^{-1}$ within the avalanche detaching area $(250-500 \mathrm{~m}$ distance from release point), to reach the peak velocity of $18.4 \mathrm{~m} \mathrm{~s}^{-1}$ (850-1050 $\mathrm{m}$ ground distance from release point) and then decrease below $15 \mathrm{~m} \mathrm{~s}^{-1}$ afterwards. The lack of data between 700 and $800 \mathrm{~m}$ distance corresponds to a blind area
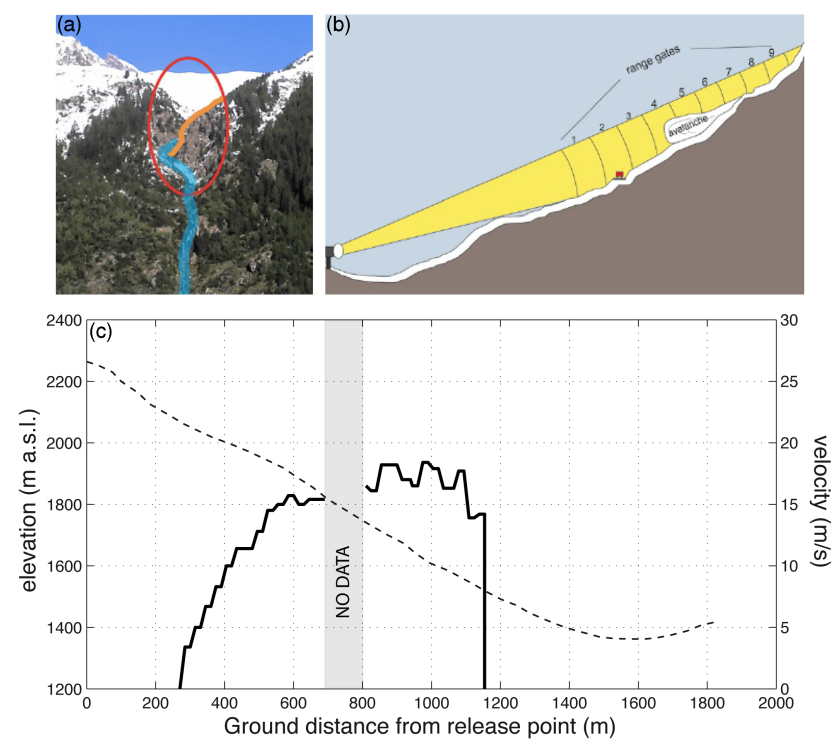

Figure 2. View of the Grosstal avalanche path (blue line) from the monitoring radar (a). The red circle denotes the sector of the avalanche path monitored by the radar, while the orange line identifies a ridge that prevents monitoring of the path between 700 and $800 \mathrm{~m}$ ground distance from release point. The radar is able to detect the moving front of the avalanche in several range gates (b) within a ground distance from the release point spanning from $\sim 250$ to $1150 \mathrm{~m}$ from the release point (red are in a). (c) Velocity profile of the 23 December 2012 event as measured by the radar. The avalanche path profile is represented by the black dashed line.

of the Doppler radar field of view, while the drop of velocity at $1150 \mathrm{~m}$ distance corresponds to the avalanche moving outside the radar field of view. Recorded velocity for the 23 December 2012 event is in the range commonly reported for snow avalanches (see Havens et al., 2014, for a review).

Radar monitoring of snow avalanches is generally extremely reliable. Its penetration efficiency is limited only by the intense snowfalls and false alarms are reported only in case of strong winds.

\subsection{The infrasound array, instrument setup and data processing}

The infrasound monitoring system deployed in Ischgl (Austria) between December 2012 and April 2013 consisted of a four-element infrasound array with a triangular geometry and an aperture (maximum distance between two elements) of approximately $150 \mathrm{~m}$. The array elements were equipped with differential pressure transducers, with a sensitivity of $25 \mathrm{mV} \mathrm{Pa}^{-1}$ in the frequency band 0.01 to $500 \mathrm{~Hz}$. Pressure data were recorded at the sampling rate of $100 \mathrm{~Hz}$ with a 24-bit Guralp CMG-DM24 digitizer and GPS time synchronization. The array was installed in a forest close to the Doppler radar and facing different avalanche paths including 
the Grosstal avalanche path (Fig. 1). The array is deployed in an almost flat surface inclined $\sim 15^{\circ}$ towards NW.

Arrays are typically used to investigate the whole infrasonic wave-field regardless the position of the infrasonic source. For this reason avalanches occurring from different avalanche paths around the array and with various sourceto-receiver distances (Fig. 1a) are possibly to be detected by using array processing. Limitations of array detection techniques are related to the signal-to-noise ratio, which depends on the local noise and strength of the source as well as propagation effects from the source to the receiver.

The use of an array instead of a single sensor allows for an increase of the signal-to-noise ratio and better identification of signal from noise. Array signal processing is based on the assumption that a signal is coherent at different sensors, while noise does not show any correlation. One infrasound detection is defined when, in a given time window $(5 \mathrm{~s}$ in our case), coherent infrasound signal is recorded across the array and multichannel cross-correlation exceeds a fixed threshold (e.g., Ripepe and Marchetti, 2002). An infrasonic transient, e.g., a snow avalanche, consists typically of multiple detections as a consequence of event duration and processing windowing (Fig. 3).

Following Ulivieri et al. (2011), the time shifts $d t_{i j}$ between different couples of sensors $(i, j)$ is used to derive the infrasonic ray path of a planar wave field propagating across the array. This is fully described in terms of back azimuth $(\alpha)$ and apparent velocity $\left(c_{\mathrm{a}}\right)$. Back azimuth identifies the direction from where the signal is coming from (Fig. 1c) with azimuthal resolution being strongly related to the array aperture and frequency content of recorded infrasound.

In the specific case of the Grosstal avalanche channel remotely controlled explosive activity is performed regularly from fixed stations (Kogelnig et al., 2012) deployed in the avalanche starting area at a distance of $\sim 1800 \mathrm{~m}$ from the infrasound array. Such explosions are always detected with the infrasound array and allowed us to evaluate the error of backazimuth measurement with the array. The difference between back azimuth derived with the infrasound array and real back azimuth to the explosive towers is $<1^{\circ}$, thus indicating a limited effect of wind in azimuth deflation.

The apparent velocity is the velocity measured for a signal propagating across the plane defined by the elements of the array (Fig. 1c) and is directly reflecting the elevation of the infrasonic source

$c_{\mathrm{a}}=\frac{c}{\sin (\gamma)}$,

where $\gamma$ is the infrasonic take-off angle, defined as the angle between the infrasonic ray and the normal vector to the surface represented by the array plane $(\hat{n})$, while $c$ is the sound propagation velocity at local temperature and humidity. It is clear from Eq. (1) that the apparent velocity for a linear ray path depends on the elevation of the source. In the case of a source located right above the array the take-off angle

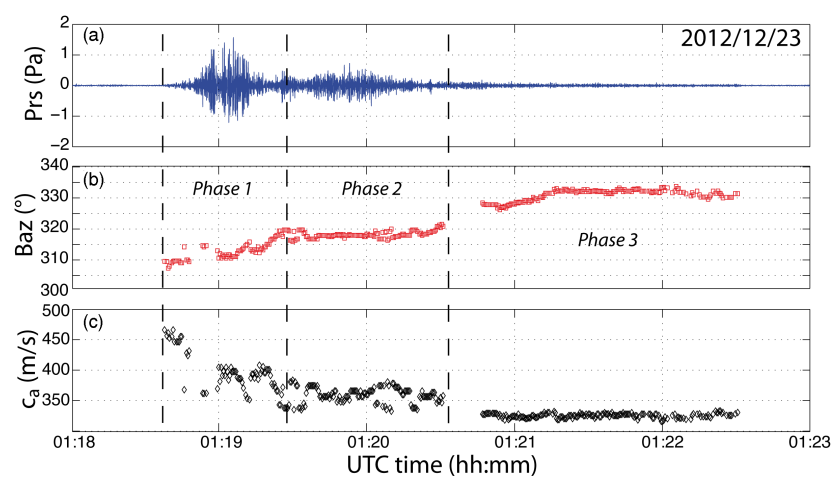

Figure 3. Infrasonic record (a), back azimuth (b) and apparent velocity (c) of infrasound detections of the 23 December 2012 snow avalanche from Grosstal (Fig. 1). The vertical dashed lines define the three different phases of the signals which are further discussed in the text.

would be $0(\gamma=0)$ and apparent velocity would be infinite $\left(c_{\mathrm{a}}=\infty\right)$, consistent with a signal being recorded simultaneously at all the elements of the array.

It is clear that in case of a moving source of infrasound, the derived back azimuth and apparent velocity are expected to change through time reflecting the time-varying position of the source. In the specific case of a snow avalanche that flows downhill, the source elevation will decrease, take-off angle will increase and a negative gradient of apparent velocity will be expected. Similarly, back azimuth is expected to change through time reflecting the channel morphology. Accordingly, we suggest that infrasound array analysis can contribute both to the study of the avalanche kinematics, in terms of the time-varying wave parameters, as well as to remotely identify event occurrence, with direct effects in both research and monitoring. These two aspects are further discussed in the following sections.

\section{Avalanche kinematics and evolution inferred from infrasound observations}

On 23 December 2012, an avalanche occurred from the Grosstal channel at (01:18:30 UTC) and was recorded both with the radar and the infrasound array (Figs. 1-3). The array analysis was performed on band-pass $(0.5-20 \mathrm{~Hz})$ filtered infrasonic data, showing multiple detections with varying back azimuth and apparent velocity. The multiple detections are a consequence of the signal windowing $(5 \mathrm{~s})$ and show a continuous migration of back azimuth (from 309 to $330^{\circ} \mathrm{N}$ ) of $\sim 20^{\circ}$ and a reduction of apparent velocity from 460 to $330 \mathrm{~m} \mathrm{~s}^{-1}$ as expected for a downhill moving front. Measured apparent velocity is consistent with the geometry of the avalanche path. The elevation difference $(\sim 850 \mathrm{~m})$ and ground distance $(\sim 1800)$ between the array and the avalanche release zone result in a take-off angle $(\gamma)$ of $64^{\circ}$, which reduces to $\sim 49^{\circ}$ once the $\sim 15^{\circ}$ inclination of the array is considered. According to Eq. (1) and assuming a sound 
propagation velocity $(c)$ of $333 \mathrm{~m} \mathrm{~s}^{-1}$ at ambient temperature of $3{ }^{\circ} \mathrm{C}$, this value of the take-off angle $\left(\gamma=49^{\circ}\right)$ corresponds to an apparent velocity $\left(c_{\mathrm{a}}\right)$ of $440 \mathrm{~m} \mathrm{~s}^{-1}$ for infrasound produced by the avalanche in the uppermost portion of the Grosstal avalanche channel. Such a value is in quite good agreement with the value of $460 \mathrm{~m} \mathrm{~s}^{-1}$ measured from infrasound array analysis (Fig. 3).

The infrasound signal of the 23 December 2012 Grosstal avalanche shows three major phases. The first phase lasts approximately $\sim 50 \mathrm{~s}$ (from 01:18:35 to 01:19:25 in Fig. 3a), showing an energetic wave packet with the maximum amplitude of infrasonic pressure at the array of $1.2 \mathrm{~Pa}$, and shows a back-azimuth rotation of $\sim 10^{\circ}$ (from 309 to $320^{\circ} \mathrm{N}$ ) and a decay of apparent velocity from $\sim 460$ to $\sim 360 \mathrm{~m} \mathrm{~s}^{-1}$ (Fig. 3a). The second phase lasts $\sim 65 \mathrm{~s}$ (from 01:19:25 to 01:20:30 in Fig. 3a) and is characterized by a lower amplitude $(\sim 0.5 \mathrm{~Pa})$ and stable values of back azimuth at $318^{\circ} \mathrm{N}$ and apparent velocity at $360 \mathrm{~m} \mathrm{~s}^{-1}$. The third phase lasts $\sim 100$ s (from 01:20:45 to 01:22:30 in Fig. 3a) and shows lower amplitude $(<0.1 \mathrm{~Pa}$ ) stable values of apparent velocity at $\sim 330 \mathrm{~m} \mathrm{~s}^{-1}$ while back azimuth keeps rotating 10 more additional degrees from 320 to $330^{\circ} \mathrm{N}$ (Phase 3 in Fig. 3). This pattern of back azimuth and apparent velocity is reflecting the avalanche kinematics in terms of extended moving source radiating infrasound during different stages of the flow.

We suggest that the first phase is likely dominated by infrasound produced by the avalanche front and changes in the back azimuth and apparent velocity reflect the front trajectory. This phase is indeed characterized by back azimuth rotating from 309 to $320^{\circ} \mathrm{N}$ and this interval matches most of the avalanche path (Fig. 4). The stable position of the infrasound source during the second phase could be explained as the rapid deceleration of the avalanche flow induced by the change of topographic slope (Delle Donne et al., 2014). The third phase, which strongly recalls infrasonic waveforms recorded for snow avalanches at the Vallée de la Sionne test site and interpreted as being produced by the dynamics of avalanche deposition in the run-out zone (Kogelnig et al., 2011). This third phase is likely produced by a source extending horizontally (back azimuth varies between 320 and $330^{\circ} \mathrm{N}$ ) but not vertically (stable apparent velocity) and possibly reflects the accumulation of snow deposits in the valley (Fig. 1a).

In order to fully understand the meaning of these results, it is important to keep in mind that array analysis allows the detection of the most energetic source of infrasound recorded at any given time. If a signal from multiple sources is recorded at the same time, only the most energetic signal will be detected. Accordingly, it is reasonable to assume that despite snow deposit accumulation in the valley starting immediately when the avalanche front reaches the valley bottom (i.e., at the end of the first phase, for back-azimuth value of $320^{\circ} \mathrm{N}$ ), it is likely that it will not be detected by the array processing
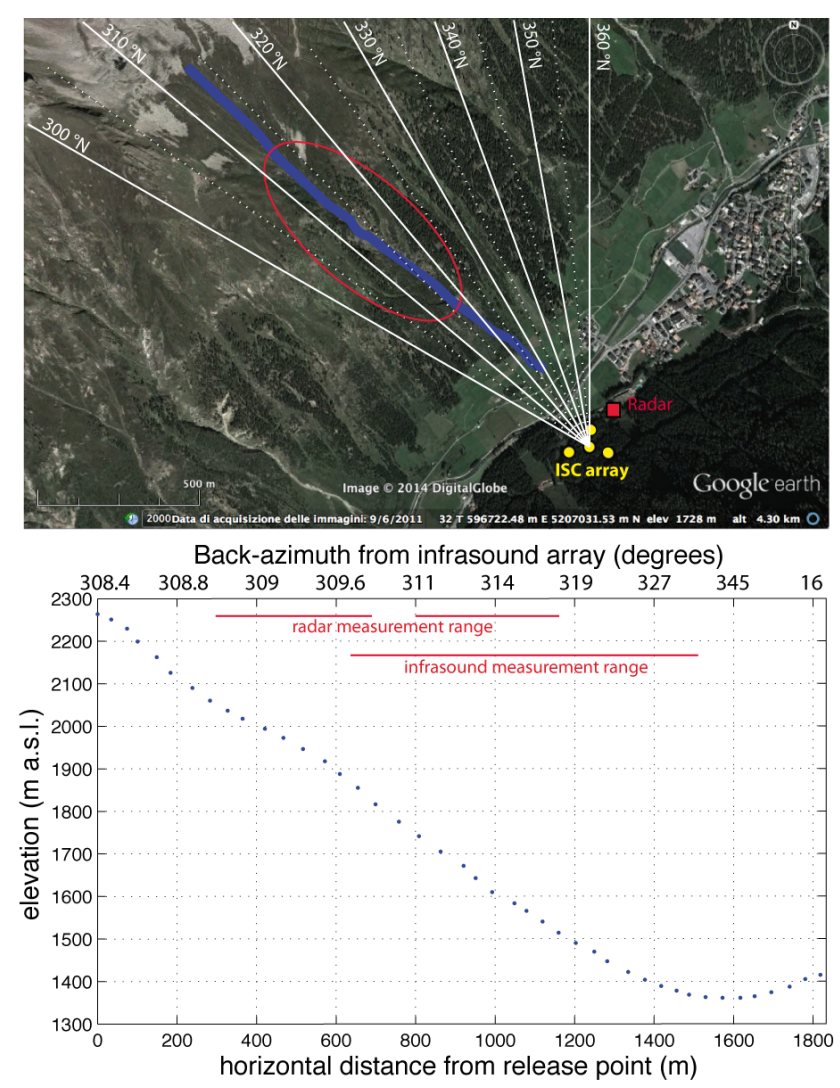

Figure 4. Upper panel: view of the Grosstal avalanche path (blue) showing the theoretical values of back azimuth to the array (white) and target area of the Doppler radar (red). Lower panel: the Grosstal avalanche path as a function of infrasonic back azimuth to the array and horizontal distance from release point.

until the larger amplitude infrasound radiated during phase 2 of the avalanche is eventually over.

\section{Comparison of infrasound and radar observation to retrieve avalanche front propagation velocity}

Infrasound has been successfully used to track extended down-hill moving sources, proving its efficiency in monitoring density currents flows (Ripepe et al., 2009; Delle Donne et al., 2014). Ulivieri et al. (2011) tracked the motion of an avalanche front at a source-to-receiver distance of $2 \mathrm{~km}$ with infrasonic back azimuth and compared it to video imagery showing that infrasonic back azimuth matches the migration of the avalanche front and could be used to derive infrasound velocity. More recently Havens et al. (2014) evaluated instantaneous front velocity of a snow avalanche by applying Fisher statistics of infrasound array observations along the section of the avalanche path. Here we present a procedure to derive automatically the avalanche front velocity directly from infrasound array observations based on the conversion of infrasound back azimuth into position of the moving source of infrasound along a given avalanche path. 


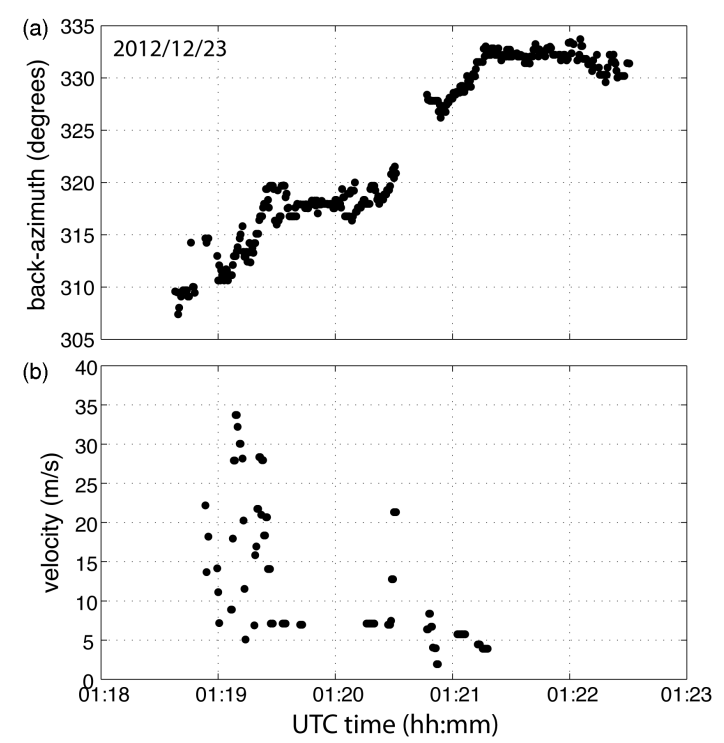

Figure 5. Back azimuth of the 23 December 2012 Grosstal avalanche (a) and instantaneous avalanche front velocity (b) derived from the infrasound array analysis.

From a digital elevation map of the area with $10 \mathrm{~m}$ resolution we calculate the avalanche path and evaluate for each point the absolute position $\left(x_{i}, y_{i}, z_{i}\right)$ and the expected back azimuth $\left(\mathrm{az}_{i}\right)$ (Fig. 4a). From the position of the avalanche path in space, we evaluate the horizontal $\left(h_{i}\right)$ and slant distance $\left(l_{i}\right)$ between successive points $(i-1$ and $i)$ along the path and the corresponding back azimuth at the array:

$$
\left\{\begin{array}{l}
h_{i}=\sqrt{\left(x_{i}-x_{i-1}\right)^{2}+\left(y_{i}-y_{i-1}\right)^{2}} \\
l_{i}=\sqrt{\left(z_{i}-z_{i-1}\right)^{2}+h_{i}^{2}} \\
\mathrm{az}_{i}=\tan ^{-1}\left(\frac{x_{i}-x_{\mathrm{a}}}{y_{i}-y_{\mathrm{a}}}\right)
\end{array}\right.
$$

where $x_{\mathrm{a}}$ and $y_{\mathrm{a}}$ are the coordinates of the central element of the array. The slant $(L)$ and ground distance $(H)$ are defined by the sum of the different portions along the whole avalanche path:

$$
\left\{\begin{array}{l}
H=\sum_{i}^{N} h_{i} \\
L=\sum_{i}^{N} l_{i}
\end{array}\right.
$$

This geometrical discretization of the avalanche path allows to link infrasonic back azimuth $\left(\mathrm{az}_{i}\right)$ with the position of the avalanche front along the path $\left(x_{i}, y_{i}, z_{i}\right)$ and thus to relate variation of infrasonic back azimuth $\left(\Delta \mathrm{az}_{i}=\mathrm{az}_{i}-\mathrm{az}_{j}\right)$ to distances $\left(h_{i}, l_{i}\right)$ traveled by the avalanche front in time (Fig. 4b).

It is clear from Fig. 4a that the relative positions of the avalanche path and the infrasound array result into a nonhomogeneous azimuthal resolution of the path. In the case of the avalanche starting area (between 0 and $450 \mathrm{~m}$ in Fig. $4 \mathrm{~b}$ ),

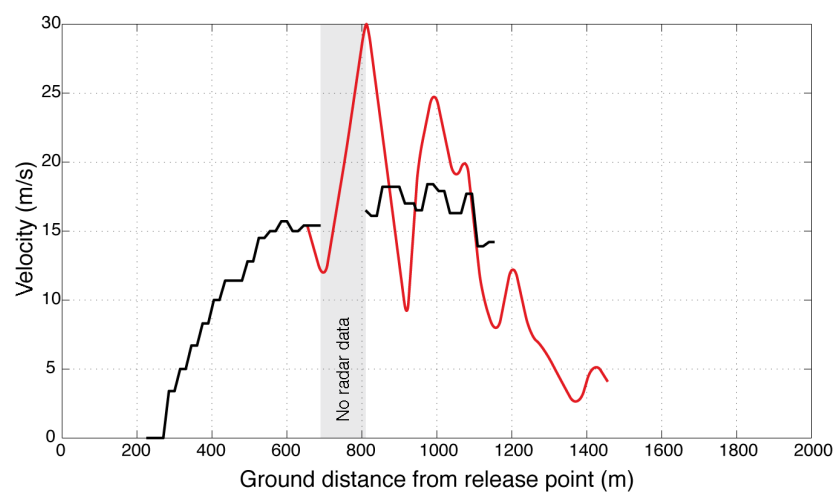

Figure 6. Comparison of avalanche front velocity as measured by the radar (black line) and derived from infrasound array analysis (red line). Gray bar show the velocity of different sectors of the avalanche path derived from infrasound array.

for example, the distance of 400-500 $\mathrm{m}$ corresponds to a limited azimuthal variation $\left(<1^{\circ}, 309-310^{\circ} \mathrm{N}\right.$; Fig. $\left.4 \mathrm{~b}\right)$, while within the avalanche main channel (between 450 and $1250 \mathrm{~m}$ in Fig 4b) the resolution is significantly better, being the horizontal distance of $\sim 800 \mathrm{~m}$ tracked by a back-azimuth interval of $\sim 10^{\circ}\left(310-320^{\circ} \mathrm{N}\right)$. Azimuthal resolution is maximum in the accumulation zone (between 1250 and $1600 \mathrm{~m}$ in Fig. 4b), which is tracked by a back-azimuth variation exceeding $10^{\circ}\left(320-330^{\circ} \mathrm{N}\right)$.

Once the geometrical relation between infrasound back azimuth and distance along the avalanche path is derived (Eq. 2), we evaluate the avalanche front velocity as a function of time. Variations of infrasonic back azimuth can easily be converted into the distance traveled by the front as a function of time, thus providing the instantaneous front velocity (Fig. 5).

This procedure, once applied to the infrasonic detections of the 23 December 2012 Grosstal avalanche, shows instantaneous velocity ranging from $\sim 10$ up to $35 \mathrm{~m} \mathrm{~s}^{-1}$ (mean $\left.20 \mathrm{~m} \mathrm{~s}^{-1}\right)$ at the beginning of the event (01:19:00-01:19:30). Front velocity becomes stable around $\sim 6 \mathrm{~m} \mathrm{~s}^{-1}$ between 01:19:30 and 01:20:30, when back azimuth shows a limited rotation from 317 to $319^{\circ} \mathrm{N}$. Velocity increases again at 01:20:30, reaching values of $22 \mathrm{~m} \mathrm{~s}^{-1}$ and then gradually tends to 0 . This secondary velocity peak is recorded for backazimuth rotation from 319 to $322^{\circ} \mathrm{N}$, which corresponds to the channel entering into the valley.

Figure 6 shows the comparison between the velocity measured directly by the radar and the velocity derived from infrasound array observations. Despite the generally larger values, possibly to be explained as the velocity along the radar line of sight an underestimate of the real front velocity, infrasound-derived velocity appears to match the general trend of radar measurement. For ground distances ranging between 650 and $1100 \mathrm{~m}$, the difference between velocity derived from infrasound and measured by the radar peaks 


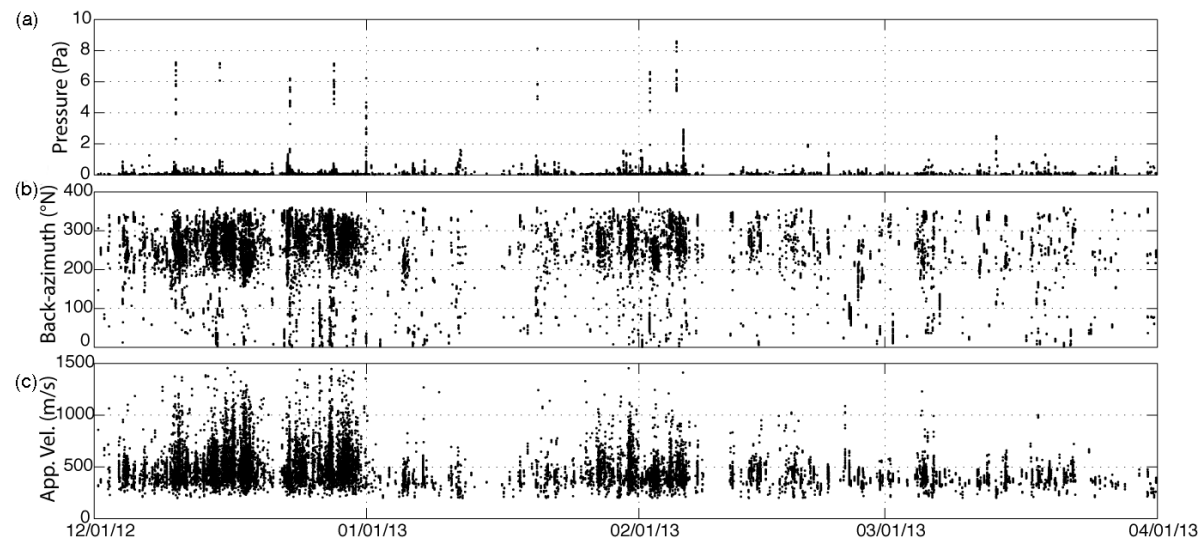

Figure 7. Results of infrasound array processing for the period of analysis (December 2012-March 2013) showing amplitude (a), back azimuth (b) and apparent velocity (c) of calculated infrasound detections.

at $13 \mathrm{~m} \mathrm{~s}^{-1}$ but is generally below $3 \mathrm{~m} \mathrm{~s}^{-1}$. Moreover, infrasound analysis extends radar measurements outside the radar field of view along the avalanche path (between 700 and $800 \mathrm{~m}$ of ground distance) and in the avalanche depositional area (> $1100 \mathrm{~m}$ ground distance). The good matching between the avalanche front velocity measured by the radar and estimated from the infrasound array (Fig. 6) suggests that the velocity of an avalanche front can be derived from infrasound observation, once the topographic profile of the avalanche path is known. In agreement with previous studies (Yamasato, 1997; Ripepe et al., 2009; Delle Donne et al., 2014; Havens et al., 2014), our analysis provides the evidence that infrasound analysis can be efficiently used to estimate the front velocity of a snow avalanche and improves the procedure also for avalanche paths that are not optimally located with respect to the array.

\section{Automatic avalanche identification}

Based on previous analysis of the Grosstal avalanche, we show how some of the peculiar features described above can be used as criteria for a robust automatic identification of snow avalanche events. Infrasound array analysis was applied to data collected at the array during December 2012March 2013 and band-pass filtered between 0.5 and $20 \mathrm{~Hz}$, leading to a total of 31770 infrasonic detections, corresponding to a mean rate of 262 detections/day (Fig. 7). Amplitude of infrasonic detections is generally small and limited to $0.2 \mathrm{~Pa}$, with higher values at the array being commonly associated with controlled explosions. Back azimuth of infrasound detections tend to cluster in the $200-330^{\circ} \mathrm{N}$ range. The propagation velocity has a mean value of $330 \mathrm{~m} \mathrm{~s}^{-1}$, which is consistent with an air temperature of $\sim 0^{\circ} \mathrm{C}$, in agreement with what expected during the winter at this latitude.

Many of the observed detections might result from a wide range of sources producing infrasound in the $0.5-20 \mathrm{~Hz}$ frequency range, thus including the range $(1-5 \mathrm{~Hz})$ typically radiated by snow avalanches (e.g., Bedard, 1989) and acting at various ranges all around the array. These might include microbarom, severe weather (i.e., thunderstorms and lightnings), anthropogenic sources (industrial plants, airplanes) and other natural processes (e.g., meteorites, earthquakes).

Based on the evidence that snow avalanches are detected with predictable behavior of back azimuth and apparent velocity (Figs. 4 and 5) we extracted from the whole data set (Fig. 7) all possible avalanches that occurred from Grosstal. The threshold criteria used to automatically detect avalanches from Grosstal are the following: (i) detections must show a back-azimuth rotation $>5^{\circ}$ and have values included in the $310-320^{\circ} \mathrm{N}$ range; (ii) decrease of apparent velocity of $>10 \mathrm{~m} \mathrm{~s}^{-1}$; (iii) duration of the event must be longer than $10 \mathrm{~s}$; (iv) peak amplitude at the array must be larger than $0.05 \mathrm{~Pa}$. While the last two criteria are related to the size of the event and limit the analysis to the most significant events, the first two criteria are reflecting the kinematics nature of avalanches of being a moving source of infrasound and limit the analysis to Grosstal avalanche path.

Out of the 31770 infrasound detections recorded between December 2012 and March 2013, only three events appear to match these threshold criteria (Fig. 8). All appear to show the same kinematic behavior. The 10 December 2012 infrasound event shows a smaller back-azimuth variation of $\sim 5^{\circ} \mathrm{lim}$ ited to $320^{\circ} \mathrm{N}$, and its duration ( $\left.\sim 80 \mathrm{~s}\right)$ and is significantly shorter than the others $(>200 \mathrm{~s})$, indicating a shorter run-out of the event.

While two of the events extracted automatically (23 December 2012 and 11 March 2013) are consistent with avalanches also recorded by the radar, for the first event (10 December 2012) we have no visual observations or radar detections. However, at the time of the event snowfall was intense and this might have prevented the observation of the deposit and limited the radar efficiency; thus it is not straightforward to exclude the occurrence of an event. Based on this result, we can conclude that the automatic avalanche identification based on array processing analysis did not produce 


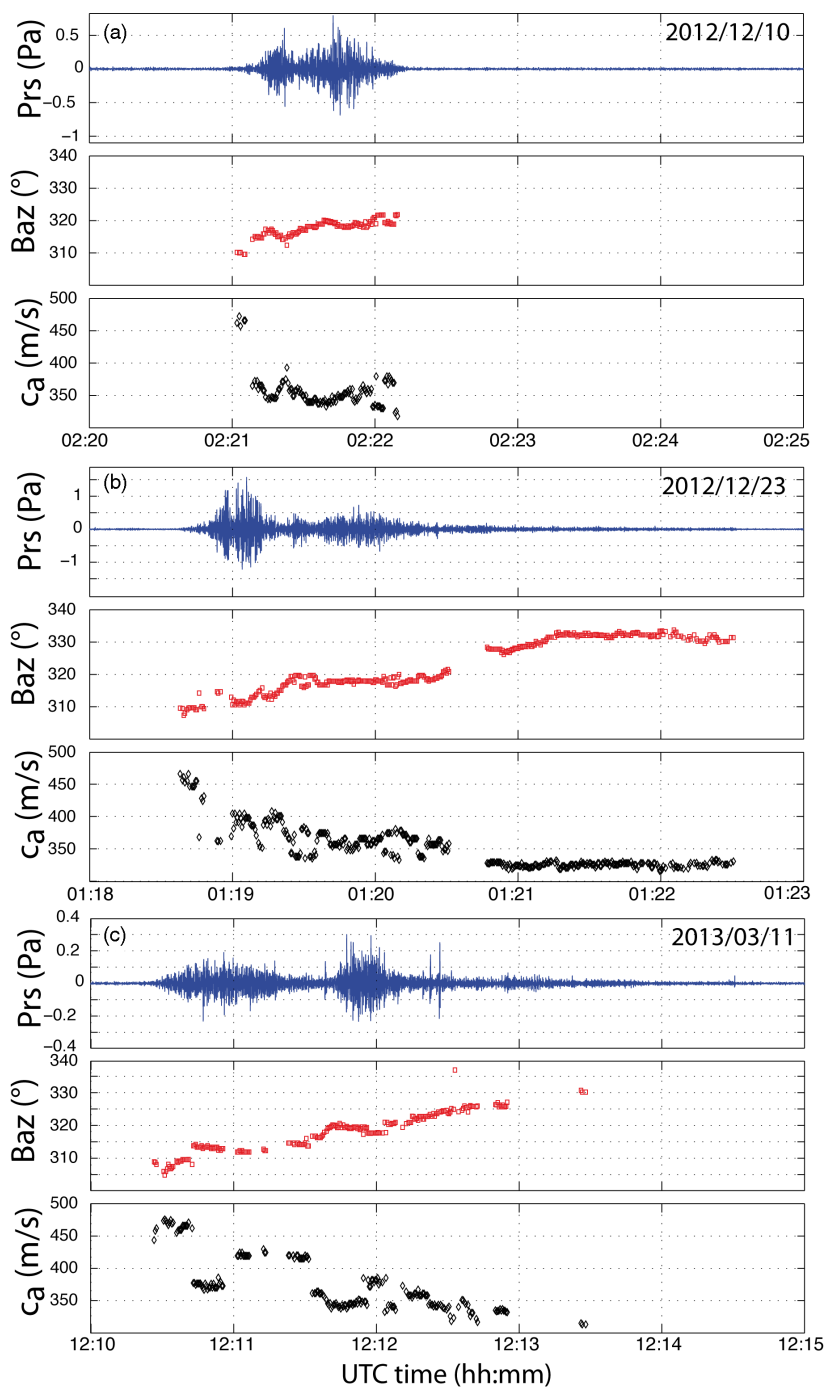

Figure 8. Infrasonic record at the central element of the array (blue), back azimuth (red) and apparent velocity (black) of infrasound detections for the three events extracted automatically from the whole data set.

any false alarm, with respect to the radar, for avalanches occurring from Grosstal.

Moreover, it is worth noting that the three extracted events share, together with wave parameters, also similar waveforms, dominated by two major phases that appear to be produced from the same sections of the avalanche path. The first phase is indeed associated with back-azimuth values of 308$320^{\circ} \mathrm{N}$ and appears to be radiated from the avalanche starting zone and avalanche channel (Fig. 4) while the second phase appears to be radiated with stable back azimuth of $\sim 320^{\circ} \mathrm{N}$ consistent with the end of the avalanche channel. The relative difference in amplitude that can be observed between the 23 December 2012 event and the 11 March 2013 event might be explained with a different dynamic, where the 23 December 2012 event is dry in the starting zone and wet in the deposition zone, thus resulting in a different efficiency of infrasound radiation.

The good results obtained for the Grosstal avalanche (Fig. 8) allowed us to extend the automatic thresholds in order to detect snow avalanches occurring also all around the array. In particular the same threshold criteria have been applied except the limitation to a specific azimuthal sector.

New thresholds expand the number of events to only 103 out of the 31770 detections. All the events have a backazimuth rotation between 5 and $60^{\circ}\left(\right.$ mean $\left.=10^{\circ}\right)$ and a mean decrease of apparent velocity of $\sim 40 \mathrm{~m} \mathrm{~s}^{-1}$. Most of the automatically extracted events are located west of the array within a main back-azimuth interval from 170 to $360^{\circ} \mathrm{N}$ (Fig. 9), consistent with avalanches released from the northern $\left(240-20^{\circ} \mathrm{N}\right)$ and southern flank $\left(170-240^{\circ} \mathrm{N}\right)$ of the valley. Very few infrasonic signals have back azimuth ranging between 60 and $170^{\circ} \mathrm{N}$, which corresponds to a topographic sector where no avalanche have been observed.

According to this infrasonic analysis avalanches activity peaked on 23 December 2012, with a maximum of 15 events day ${ }^{-1}$. Moderate activity was recorded on 10,11 , 28 December 2012 and 12 March 2013 (Fig. 9c) when more than five infrasonic events day ${ }^{-1}$ were detected and avalanches from Grosstal did actually occur (Fig. 8).

For the specific case of the 22-23 December 2012 peak activity, 16 infrasonic events (Fig. 10) were automatically identified during a 6-hour-long time period (between 21:00 UTC on 22 December and 03:00 UTC on 23 December). These infrasonic events showed back azimuth being consistent with snow avalanches possibly occurring both in the northern (around Grosstal avalanche) and southern sectors of valley nearby the array. In the morning, deposits from at least six avalanches from the paths around Grosstal could be observed, indicating the high efficiency of our automatic system to locate and identify infrasound generated by snow avalanches.

\section{Discussion and conclusions}

During the last 10 years, infrasound analysis of snow avalanches is becoming one of the most promising tools to monitor snow avalanches (e.g., Scott et al., 2007; Ulivieri et al., 2011; Havens et al., 2014; Thüring et al., 2015), but the use of infrasonic arrays as a permanent monitoring tool is still limited to temporary experimental sites. Unlike Doppler radars (Rammer et al., 2007; Vriend et al., 2013), which target a specific single avalanche path, infrasound array analysis can be applied to multiple paths covering large areas around the array, with a resolution depending on the relative position of the array and the avalanche path (Fig. 4). However, while Doppler radar monitoring is considered to be a reliable monitoring system for snow avalanches, the utility of infrasound is still debated because the difficulties of recognizing univocally signals generated by snow avalanches are believed to produce many false alarms. One of the main aims of on- 


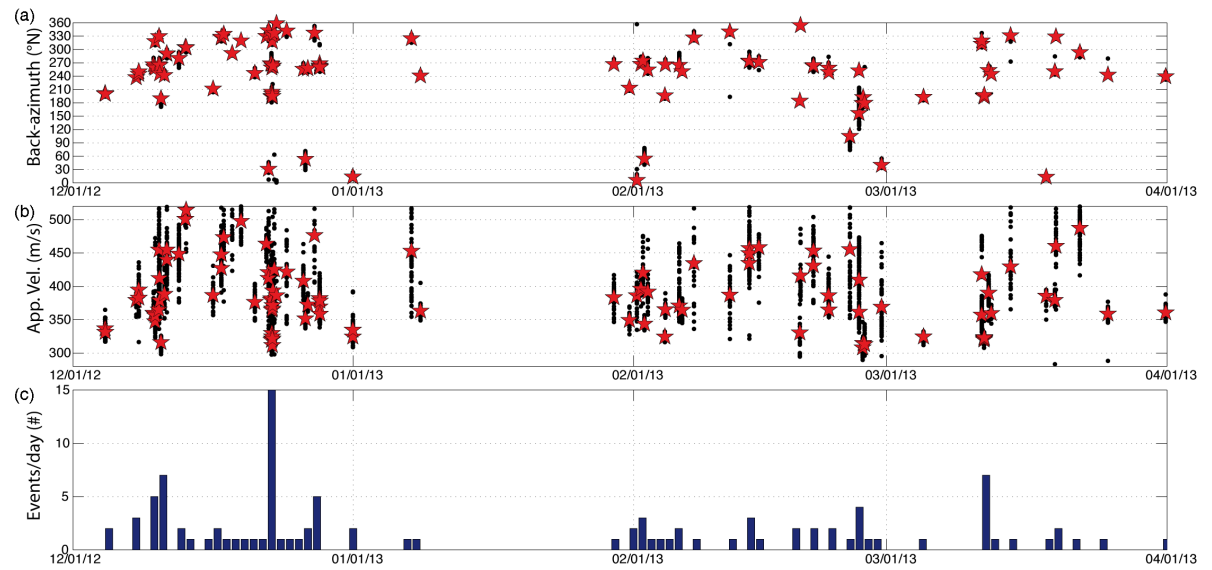

Figure 9. (a) Back azimuth and apparent velocity (b) of infrasonic detections (black dots) of 103 signals (red stars) showing infrasound wave parameters consistent with what expected by snow avalanches identified by the infrasound array between December 2012 and March 2013. (c) Number of events day ${ }^{-1}$ during the 2012-2013 winter season.

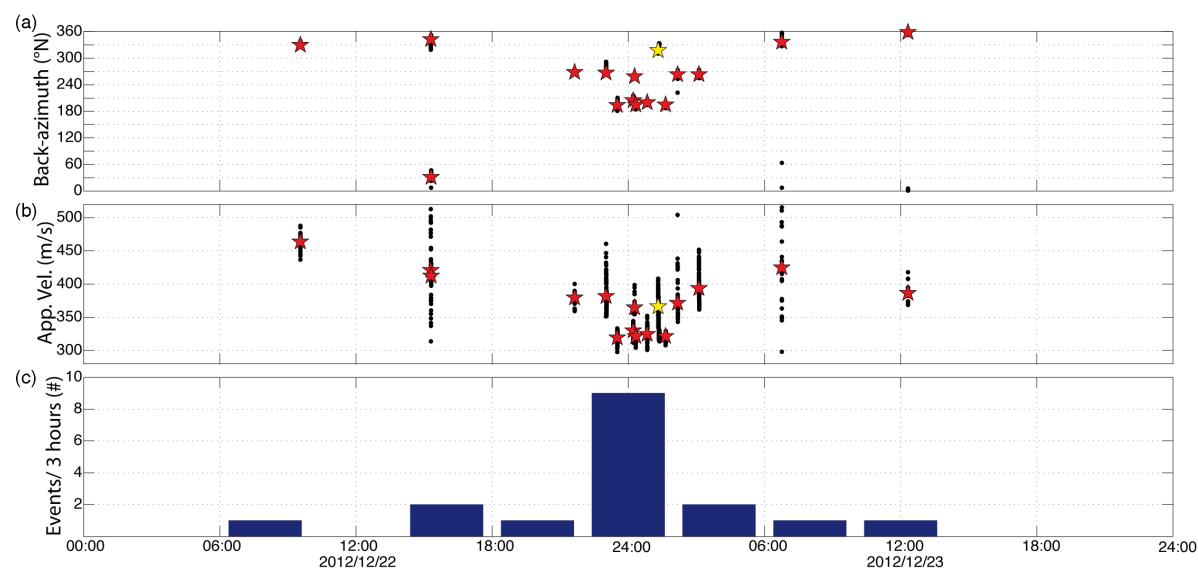

Figure 10. (a) Back azimuth and apparent velocity (b) of infrasonic detections (black dots) for 16 events (stars) recorded during 22 and 23 December 2012. The yellow star corresponds to the 23 December 2012 Grosstal avalanche (Figs. 1-3), which was detected by the radar. Number of events every $3 \mathrm{~h}$ (c) shows a significant increase since the afternoon of 22 December.

going research on avalanche infrasound is the improvement of event identification reliability with approaches spanning from infrasound array processing (e.g., Scott et al., 2007; Ulivieri et al., 2011) to neural network analysis (Thüring et al., 2015).

A snow avalanche front moving downhill behaves as a moving source of infrasound, which is continuously changing its position in the 3-D space. We show here how infrasound array analysis is able to follow these changes in terms of rotation of the propagation back azimuth and of decrease in the apparent velocity. These two parameters are indeed reflecting a downhill moving source and are thus distinctive of snow avalanches as well as most of the density currents able to generate infrasound (Ripepe et al., 2009; Delle Donne et al., 2014; Havens et al., 2014) and can be used to efficiently monitor avalanches automatically and in real time.
We showed how avalanche kinematics, once back azimuth and apparent velocity of infrasonic detections are properly analyzed, could be used to fix threshold criteria for automatic identification of infrasonic signals generated by avalanches from infrasonic signals of different origin (Fig. 9). In our study the automatic extraction procedure appeared quite successful, with no false alarms with respect to the Doppler radar monitoring system; despite the fact that a validation over a longer data set and collection in different areas might improve results, infrasound could provide the number and the time of occurrence of snow avalanches occurring all around the array (Fig. 9), which are key for a proper validation of avalanche forecast models (Schweizer and van Herwjinen, 2013).

The migration of infrasonic back azimuth projected on the topography provides an estimate of the instantaneous velocity of the moving front (Figs. 4 and 5). We showed how in- 
frasound recorded with a small aperture array can be used to estimate the avalanche front velocity, which nicely fits with velocity measured directly by a pulsed Doppler radar. We suggest that this procedure can be applied to multiple paths around the array and it provides reliable results even if the path geometry is not optimal in terms of back azimuth to the array, as in the case of the Grosstal avalanche.

Despite a systematic field validation should be still required, the results presented so far already highlight the potential benefit of infrasound array analysis for the research of avalanche kinematics as well as avalanche remote detection and risk management. The avalanche activity near Ischgl during the night of 22-23 December 2012 was detected by the Doppler radar only at 01:18 UTC on 23 December, while infrasound array analysis provides evidence that avalanche activity already increased in the area $\sim 3-4 \mathrm{~h}$ before (Fig. 10). In this specific case, an infrasound array monitoring system might have delivered automatically and in real time an early warning of increased avalanche activity, with a strong impact on risk management.

Acknowledgements. We thank Emma Surinach and an anonymous reviewer for their careful review. We thank the Ischgl Avalanche Team and in particular Albert Siegele for providing field and observational data of avalanches released from Grosstal and the municipality of Ischgl for providing the radar data. E. Marchetti and M. Ripepe were supported by the European Union ARISE FP7 project (GA 284387).

Edited by: P. Bartelt

Reviewed by: E. Surinach and one anonymous referee

\section{References}

Adam, V., Chritin, V., Rossi, M., and Van Lancker, E.: Infrasonic monitoring of snow-avalanche activity: what do we know and where do we go from here?, Ann. Glaciol., 26, 324-328, 1998.

Bedard, A.: Detection of avalanches using atmospheric infrasound, Proceedings of the Western Snow Conference, edited by: Shafer, B., Western Snow Conference, April 1989, Colorado State University, Fort Collins, CO, USA, 52-58, 1989.

Chritin, V., Rossi, M., and Bolognesi, R.: Acoustic detection System for Operational Avalanche Forecasting, Proceeding of International Snow Science Workshop, Banff, Alberta, Canada, 6-11 October 1996, 129-133, 1996.

Comey, R. H. and Mendenhall, T.: Recent Studies Using Infrasound Sensors to Remotely Monitor Avalanche Activity, Proceeding of International Snow Science Workshop, Jackson, WY, USA, 1924 September 2004, 640-646, 2004.

Delle Donne, D., Ripepe, M., De Angelis, S., Cole, P. D., Lacanna, G., Poggi, P., and Stewart, R.: Thermal, acoustic and seismic signals from pyroclastic density currents and Vulcanian explosions at Soufrière Hills Volcano, Montserrat, in: The Eruption of Soufrie're Hills Volcano, Montserrat from 2000 to 2010, edited by: Wadge, G., Robertson, R. E. A., and Voight, B., Geo. Soc. Mem., 39, 167-176, doi:10.1144/M39.9, 2014.

Jöbstl, L., Studeregger, A., Wurzer, A., Stock, D., and Koschuh, R.: Analysis of detected avalanches using meteorological data of nearby monitoring stations in Ischgl, Austria, J. Environm. Sci. Eng. B, 3, 87-90, 2014.

Havens, S., Marshall, H. P., Johnson, J. B., and Nicholson, B.: Calculating the velocity of a fast-moving snow avalanche using an infrasound array, Geophys. Res. Lett., 41, 6191-6198, doi:10.1002/2014GL061254, 2014.

Kishimura, K. and Izumi, K.: Seismic signals induced by snow avalanche flows, Nat. Hazards, 15, 89-100, 1997.

Kogelnig, A., Suriñach, E., Vilajosana, I., Hübl, J., Sovilla, B., Hiller, M., and Dufour, F.: On the complementariness of infrasound and seismic sensors for monitoring snow avalanches, Nat. Hazards Earth Syst. Sci., 11, 2355-2370, doi:10.5194/nhess-112355-2011, 2011.

Kogelnig, A., Wyssen, S., and Pichler, J.: Artificial release and detection of avalanches: Managing avalanche risk on traffic infrastructures: A case study from Austria, Proceedings, 2012 International Snow Science Workshop, 16-21 September 2012, Anchorage, AK, USA, 535-540, 2012.

Lacroix, P., Grasso, J.-R., Roulle, J., Giraud, G., Goetz, D., Morin, S., and Helmstetter, A.: Monitoring of snow avalanches using a seismic array: Location, speed estimation, and relationships to meteorological variables, J. Geophys. Res., 117, F01034, doi:10.1029/2011JF002106, 2012.

Leprette, B., Navarre, J.-P., Panel, J.-M., Touvier, F., Taillefer, A., and Roulle, J.: Prototype for operational seismic detection of natural avalanches, Ann. Glaciol., 26, 313-318, 1998.

McClung, D. and Schaerer, P. A.: The Avalanche Handbook, The Mountaineers Books, Seattle, WA, USA, 2006.

Rammer, L., Kern, M. A., Gruber, U., and Tiefenbacher, F.: Comparison of avalanche-velocity measurements by means of pulsed Doppler radar, continuous wave radar and optical methods, Cold Reg. Sci. Technol. 50, 35-54, doi:10.1016/j.coldregions.2007.03.014, 2007.

Ripepe, M. and Marchetti, E.: Array tracking of infrasonic sources at Stromboli volcano. Geophys. Res. Lett., 29, 2076, doi:10.1029/2002GL015452, 2002.

Ripepe, M., De Angelis, S., Lacanna, G., Poggi, P., Williams, C., Marchetti, E., Delle Donne, D., and Ulivieri, G.: Tracking Pyroclastic Flows at Soufriere Hills Volcano, EOS, Transactions American Geophysical Union, 90, 229-230, doi:10.1029/2009EO270001, 2009.

Sabot, F., Naaim, M., Granada, F., Surinach, E., Planet-Ladret, P., and Furdada, G.: Study of the avalanche dynamics by means of seismic methods, image processing techniques and numerical models, Ann. Glaciol., 26, 319-323, 1998.

Schaerer, P. and Salway, A.: Seismic and impact-pressure monitoring of flowing avalanches, J. Glaciol., 26, 179-187, 1980.

Schweizer, J. and van Herwijnen, A.: Can near real-time avalanche occurrence data improve avalanche forecasting?, Proceedings, 2013 International Snow Science Workshop, 7-11 October 2013, Grenoble-Chamonix Mont Blanc, France, 195-198, 2013.

Schweizer, J., Jamieson, J. B., and Schneebeli, M.: Snow avalanche formation, Rev. Geophys., 41, 1016, doi:10.1029/2002RG000123, 2003. 
Scott, E. D., Hayward, C. T., Kubichek, R. F., Hamann, J. C., Pierre, J. W., Corney, B., and Mendenhall, T.: Single and multiple sensor identification of avalanche-generated infrasound, Cold Reg. Sci. Technol., 47, 159-170, 2007.

Surinach, E., Sabot, F., Furtada, G., and Vilaplana, J.: Study of seismic signals on artificially released snow avalanches for monitoring purposes, Phys. Chem. Earth Pt. B, 25, 721-727, 2000.

Thüring, M. S., van Herwijnen, A., and Schweizer, J.: Robust snow avalanche detection using supervised machine learning with infrasonic sensor arrays, Cold Reg. Sci. Technol., 111, 60-66, doi:10.1016/j.coldregions.2014.12.014, 2015.

Ulivieri, G., Marchetti, E., Ripepe, M., Chiambretti, I., De Rosa, G., and Segor, V.: Monitoring snow avalanches in Northwestern Italian Alps using an infrasound array, Cold Reg. Sci. Technol., 69, 177-183, doi:10.1016/j.coldregions.2011.09.006, 2011.

Ulivieri, G., Marchetti, E., Ripepe, M., Chiambretti, I., and Segor, V.: Infrasonic monitoring of snow avalanches in the Alps, Proceedings, 2012 International Snow Science Workshop, 16-21 September 2012, Anchorage, AK, USA, 723-728, 2012.
Vallet, J., Turnbull, B., Joly, S., and Dufour, F.: Observations on powder snow avalanches using videogrammetry, Cold Reg. Sci. Technol., 39, 153-159, doi:10.1016/j.coldregions.2004.05.004, 2004.

Van Herwijnen, A. and Schweizer, J.: Monitoring avalanche activity using a seismic sensor, Cold. Reg. Sci. Technol., 69, 165-176, doi:10.1016/j.coldregions.2011.06.008, 2011.

Vilajosana, I., Khazaradze, G., Surinach, E., Lied, E., and Kristensen, K.: Snow avalanche speed determination using seismic methods, Cold Reg. Sci. Technol., 49, 2-10, doi:10.1016/j.coldregions.2006.09.007, 2007.

Vriend, N. M., McElwaine, J. N., Sovilla, B., Keylock, C. J., Ash, M., and Brennan, P. V.: High-resolution radar measurements of snow avalanches, Geophys. Res. Lett., 40, 727-731, doi:10.1002/grl.50134, 2013.

Yamasato, H.: Quantitative analysis of pyroclastic flows using infrasonic and seismic data at Unzen volcano, Japan, J. Phys. Earth, 45, 397-416, 1997. 